\title{
Chironji (Buchanania lanzan) Wonder Tree: Nutritional and Therapeutic Values
}

\author{
Neeraj $^{1}$, Vinita Bisht ${ }^{2 *}$ and Shalini Purwar ${ }^{2}$ \\ ${ }^{1}$ Jharkhand Rai University, Ranchi, Jharkhand, India \\ ${ }^{2}$ Banda University of Agriculture and Technology, Banda-210001 (U.P), India \\ *Corresponding author
}

\section{Keywords}

Deciduous forests tribal community knowledge and education

\section{Article Info}

Accepted:

20 January 2020

Available Online:

10 February 2020

\section{A B S T R A C T}

Chironji (Buchanania lanzan Spreng.) is a member of the family Anacardiaceae and it is originated in the Indian sub-continent, is an excellent multipurpose tree species. Traditional indigenous knowledge reveals the immense value of almost all parts of the plant i.e. roots, leaves, fruits, seeds and gum for various medicinal uses. Chironji (Buchanania lanzan) is an important non-wood tree species found in deciduous forests throughout the greater part of India. It is a multipurpose tree and very important plant for rural and tribal economy. It is used as a fuel, fodder, alternative host for Kusmi lac insect, and also used in cosmetic items and soaps. Seeds/ kernel are nutritional, palatable and used as a substitute of almonds in confectionery. It is widely used by Indian tribes for treating various diseases. Three major chemical constituents of potent medicinal value, namely celidoniol, vomicine, epinitol have been characterized from an organic extract of leaves. Such extracts mainly exhibit antidiabetic, anti hyperlipidemic, antioxidant, antiinflammatory, wound healing, antidiarrheal, antivenom activity including a host of other curative properties. Very recently, unique biomaterials and biofilms are being extracted from seeds, which promise to become a major contributor in pharmaceutical industry. At present, it is growing under forest condition as an under exploited fruit and gives monitory reward to tribal community of the country. The tree is natural wild growth in the tropical deciduous forests of Northern, Western and Central India, mostly in the States of Chhattisgarh, Jharkhand, Madhya Pradesh and in Varanasi and Mirzapur districts and Bundelkhand region of Uttar Pradesh. Chironji is a vulnerable medicinal plant, is included in the Red Data Book published by International Union for Conservation of Nature and Natural Resources. In this background, there is compelling need for developing a suitable technology facilitating easy multiplication, regeneration and conservation of the species, simultaneously imparting and disseminating proper knowledge and education to the tribal population. 


\section{Introduction}

Chironji or Charoli, (Buchanania lanzan Spreng.), a member of the family Anacardiaceae, originated in the Indian subcontinent, is an excellent tree of agro forestry. It assumes great significance due to its multifarious uses and capacity to withstand adverse climatic conditions. At present, it is growing under forest condition as an under exploited fruit and gives monitory reward to tribal community of the country. It is a medium size tree, up to 40-50 ft. height with a straight trunk. Trees have the alternate bearing nature as present in the mango. It flowers in the month of January- February and ripen in April-May.

Its bark is rough, dark grey or black, fissured into prominent squares, 1.25 to $1.75 \mathrm{~cm}$ thick, and is reddish inside. Flowering starts in the month of November and its leaves are coriaceous, broadly oblong with a rounded base. It bears fruits, each containing a single seed known as "chironji" and is quite popular as an edible nut. It avoids waterlogged areas, but occurs on yellow sandy loam soils. Tree can be easily identified by its dark grey crocodile bark with red blaze and is a good species for afforestation in bare hill slopes. Buchanania lanzan, being a vulnerable medicinal plant, is included in the Red Data Book published by International Union for Conservation of Nature and Natural Resources (IUCN) (Kritikar and Basu, 1935).

Seven species of Buchanania have been reported in India of which two $B$. lanzan (Syn. B. latifolia) and B. axillaries (Syn. angustifolia) produce edible fruits. $B$. lanceolata is an endangered species. It is found in the ever green forests of Kerala. $B$. platyneura is found in Andaman only. Other species of the genus are B. lucida, B. glabra, B.accuminata. It is reported that the fruits of B. platyneura are also edible. The B. exillaris are reported to be dwarf in size and produces excellent quality of kernel. (Chauhan et al., 2012). Among these species Buchanania lanzan Spreng is most important and widely distributed species in India. This species was first described by Mr. Hamilton, a forester in 1798 in Burma and the genus Buchanania was named after him. It was originated in the Indian sub continent, and is found in India, Burma, Nepal and few other countries (Chauhan et al, 2012). Buchanania lanzan Spreng commonly known as "Cuddaph almond", "Char", "Chironji" or Pyar is a valuable tree species found in mixed dry deciduous forest throughout the grater part of India excluding eastern Himalayan forests and arid regions of north India. The species is native to India.

\section{Socio-economic importance}

Chironji is a source of income for tribal people of Chhattisgarh and other states It is backbone of their economy. A considerable reduction in the population of Chironji in the forest and non-forest areas has been recorded (Singh et al., 2002) and facing a severe threat of extinction. Due to this, Chironji is categorized under the 195 red listed medicinal plant species of Indian origin, that requires conservation measures as reported by Foundation of Revitalization of Local Health Tradition (FRLHT), Environmental Information System (ENVIS) - Centre on Medicinal Plants, Bangalore, Govt. of India.

Fresh fruit are eaten raw having pleasant, sweetish, sub-acid flavor and consumed by local people and also sold in the village market. Chironji is mainly regarded for its costly, high-priced kernels. These kernels has almond like flavor, eaten raw or roasted form, used as cooking spice and dry fruit in sweets, kheer, meaty korma in India. All parts of this plant root, leaves, gum, bark and fruits have various medicinal applications. Chironji seeds 
are rich in nutrients and medicinal properties. Chironji is an active source of phenolics, natural antioxidants, fatty acids and minerals. Its seed oil is used to treat skin diseases, remove spots and blemishes from the face. Ethanolic and methanolic extract of Chironji roots has shown good anti-diarrheal activity and significant wound healing activity, respectively (Khatoon et al., 2015).

\section{Soil and climate}

Chirounji is very hardy plant and thrives well on rocky and gravelly red soils. Through it is very hardy tree but plants do not survive under waterlogged conditions. Well drain deep loam soil is ideal. It prefers tropical and subtropical climate and can withstand drought admirably. Chhattisgarh State is rich in forest wealth and 44.2 per cent of its geographical area is covered with forest (Anon., 2015).

\section{Conservation methods adapted for Chironji}

As far as conservation of genetic diversity of Chironji is concerned, both in-situ and ex-situ approaches should be used. In the present scenario, most appropriate strategy for Chironji germplasm conservation is to adopt immediate ex-situ conservation (i.e. field genebank and cryobanking) complemented with in-situ conservation (In-situ on-farm conservation and in protected areas such as National Parks) for this species. Ex-situ field genebanks are presently being established at horticulture research institutes of Indian Council of Agricultural Research at Godhra, Gujarat and Lucknow, Uttar Pradesh for conservation and developing advance propagation methods. Collected germplasm has been cryostored as base collection representing sizable diversity in the form of 127 accessions in the National Cryogene bank at NBPGR, New Delhi for posterity and future utilization (Malik et al., 2012).

\section{In-vitro propagation}

Sharma et al., (2005) developed a protocol for somatic embryogenesis and plantlet regeneration of Chironji (Buchanania lanzan) by immature zygotic embryos cultured on Murashige and Skoog (MS) medium supplemented with various combinations of 2,4 dichlorophenoxy acetic acid (2,4-D), 6benzyladenine (BA) and/or 1-naphthalene acetic acid (NAA). The highest frequency $(60 \%)$ of somatic embryo induction was obtained in cultures grown on MS medium fortified with $4.53 \mu \mathrm{M}$ 2,4-D, $5.32 \mu \mathrm{M}$ NAA and $4.48 \mu \mathrm{M}$ BA. The medium supplemented with $15 \mu \mathrm{M}$ abscisic acid (ABA) was most effective for maturation and germination of somatic embryos. Shende and Rai (2005) claimed to develop a tissue culture technique for the rapid clonal multiplication of Chironji. They reported multiple shoot initiation in decoated seeds cultured on MS medium enriched with various concentrations of auxins and cytokinins alone or in combination. Murashige-Skoog (MS) medium supplemented with $22.2 \mu \mathrm{M}$ of BAP and 5.37 $\mu \mathrm{M}$ of NAA promoted formation of the maximum number of shoots.

Furthermore, MS medium containing 23.3 $\mu M$ kinetin induced profuse rooting of the initiated shoots. Niratker (2016) studied invitro multiple shoot induction from shoot tips and nodal segments explants of Chironji in half strength MS medium supplemented with $1 \mathrm{mg} / \mathrm{l}$ BAP and $0.5 \mathrm{mg} / \mathrm{l}$ IAA with an average number of 3-4 shoots per explants. The most commonly used tissue explants are the meristematic ends of the plants such as the stem tip, auxiliary bud tip, and root tip. These tissues have high rates of cell division and either concentrate or produce the required growth-regulating substances including auxins and cytokinins (Akin Idowu et $a l ., 2009)$. 


\section{Vegetative propagation}

Vegetative propagation methods like chip budding and softwood grafting (Singh and Singh, 2014) are also standardized and reported in Chironji. But these are less effective due to loss availability of rootstocks and dependency on seasonal conditions. Moreover, propagation through root cutting is a very slow process (Singh et al., 2002). Srivastava (1996) reported that the tree is propagated from seeds which remain enclosed inside a hard shell. To get better germination, the shell of the fruit should be cracked carefully, he added. He further reported that fresh seeds give better germination and by using such seeds he observed $70 \%$ germination. Choubey et al., (1997) reported that best germination observed with 1 per cent $\mathrm{HgCl}$ treatment in chironji.

Vegetative propagation through soft wood grafting and chip budding was successful but rarely tried as no demand of plants has been generated in want of commercial cultivation, they reported. Shukla et al., (1999) reported that 48-hour seed soaking in ordinary water gave as high as 71 per cent seed germination. On the other hand, mechanical breaking of stony endocarp resulted in 83 percent germination. However, they mentioned that mechanical breaking is time consuming and posse's high risk of damage to embryo. They also reported that seed can be stored in air tight containers up to one year.

\section{Ethnomedicinal importance}

The tribal people often consume and sale the highly nutritious seeds to sustain and also to earn their livelihood. The seeds possess 3.0\% moisture and are rich in lipid/fat (59.0\%), protein (19.0-21.6\%), starch/carbohydrate $(12.1 \%)$, fibre $(3.8 \%)$, minerals such as calcium (279.0 mg), phosphorus (528.0 mg), iron $(8.5 \mathrm{mg})$ and vitamins such as thiamine
(0.69 mg), ascorbic acid/vitamin C (5.0 mg), riboflavin $(0.53 \mathrm{mg})$, niacin $(1.50 \mathrm{mg})$ and also contain $34-47 \%$ fatty oil. The seeds are also used as expectorant and tonic. The oil extracted from kernels is applied on skin diseases and also used to remove spots and blemishes from the face. The root is used as expectorant, in biliousness and also for curing blood diseases. The juice of the leaves is digestive, expectorant, aphrodisiac, and purgative. The gum after mixing with goat milk is used as an analgesic (singh., et al., 2002). Seed collection should be done from 2nd to 3rd week of May for quality seed collection with respect to fruit weight, kernel weight, germination percent, and chemical content i.e. oil, protein and sugar contents. Destructive harvesting could be checked by educating forest tribal population about collection of ripe fruits at proper time i.e. from 2nd to 3rd week of May without damaging the trees by organized collection (Choubey, 1997).

\section{Phytochemical profile}

This plant like many other forest plants is storehouse of important unknown phytomedicines. Till now sporadic reports have been published that reveals that specially leaf, bark, and seed are the major source of various important metabolites of great pharmaceutical value. Of late, researchers are focusing their attention on various forest plants including Chironji. The leaves are reported to contain tannins, triterpenoids, saponins, flavonoids, kaempferol-7-o'glucosides, quercetin-3rahmnoglucoside, quercetin, gallic acid, kaemferol, and reducing sugars, including a new glycoside, and myricetin-3'-rhmnoside3-galactoside (Nasim et al., 1992; Mehta et al.,2010). The bark contains tannins, alkaloids, and saponins. The seed and seed oil contains fibres, carbohydrates, mineral, fats, vitamin B1, B2, B3, C, calcium, chlorine copper, iron, magnesium, phosphorus,, 
potassium, sodium, sulfur, fatty oil, $\beta$-amyrin (Khare., 2007) . The fatty acid composition of B. lanzan seed oil, determined by urea complex formation and gas liquid chromatography is found to contain following: Myristic, $0.6 \%$; palmitic, $33.4 \%$; stearic, 6.3\%; oleic, $53.7 \%$; and linoleic, $6.0 \%$. Triglyceride compositions of the native seed oil and its randomised product are calculated from the fatty acid compositions of the triglycerides and of the corresponding 2monoglycerides produced by pancreatic lipase hydrolysis.

The oil is composed of $3.2 \%, 35.8 \%, 45.5 \%$, and $15.5 \%$ tri-saturated, monounsaturated disaturated, di-unsaturated mono-saturated and tri-unsaturated glycerides, respectively. The special characteristic of the B. lanzan seed oil is its content of $22.7 \%, 31.0 \%$, and $11.3 \%$ dipalmitoolein, dioleopalmitin, and triolein. Three major chemical constituents isolated from the methanolic extract of leaves, characterized based on chemical tests and spectral analysis such as infrared, $\mathrm{H}$ nuclear magnetic resonance, mass spectroscopy were epinitol, vomicine, and celidoniol (Mehta et al., 2011).

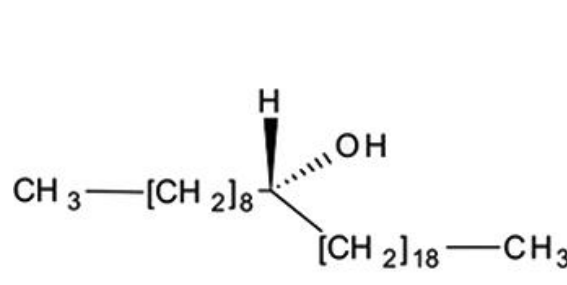

Celidoniol

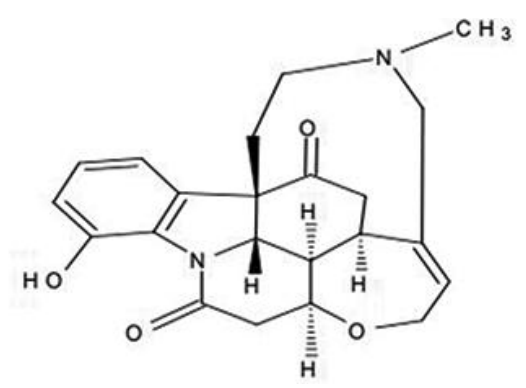

Vomicine

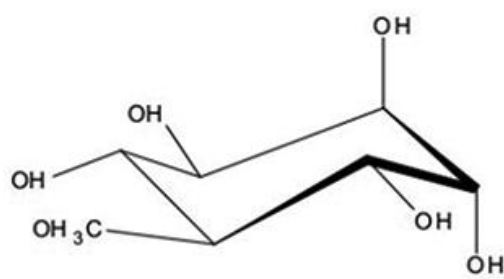

Epinitol

\section{Medicinal and curative properties}

B. lanzan is a widely used plant with a history of traditional medicinal use for the treatment of various diseases. It is used in the form of decoction to treat intrinsic haemorrhage, diarrhoea with blood and as tonic. Grown up child who has left the breast milk should be given sweet bolus prepared of $B$. lanzan kernels, madhuka (Glycyrrhiza glabra) honey, parched paddy and sugar candy. Kernels made into a powder and used with milk as aphrodisiac and in case of fever and burning sensation.

Powder of the bark mixed with honey is useful in blood dysentery. This plant has a long history of folk use in tribal societies across tropical regions of the world. At present, in this era of herbal science, in depth research is being carried out in every such plants to discover pharmaceutically active novel magic drugs. In this review, we tried to project a comprehensive account of the global effort already undertaken to explore the phytomedicinal wealth of $B$. lanzan.

\section{Anti-inflammatory and analgesic activities}

Inflammation is considered as a primary physiologic defence mechanism that helps body to protect itself against infection, burn, toxic chemicals, allergens, or other noxious stimuli. The in vivo anti-inflammatory activity is evaluated in rats by using carrageenaninduced paw edema, as an acute model and formaldehyde induced arthritis as a chronic model. The methanolic extract of $B$. lanzan kernel $(200 \mathrm{mg} / \mathrm{kg}$ body wt) significantly decreased paw volume, after oral administration of the extract (Duragkar and Bhusari., 2010). The methanolic extract of the leaves of B.lanzan at different doses used showed good anti-inflammatory activity, 
which has been done significantly, by the formation of oedema induced by carrageenan. These results are also comparable to aspirin, the reference drugs used in this study. It indicates the efficacy of the methanolic extract as a therapeutic agent in acute as well as chronic inflammatory conditions (Mehta et al., 2011).

\section{Antioxidant activity}

Antioxidants help to deal with oxidative stress which is caused by free radical damage. In vitro antioxidant activity is performed on metanolic extract of $B$. lanzan kernel by 1, 1diphenyl-2-picryl-hydrazyl (DPPH) and reducing power method. Quantitative estimation of total polyphenolic content of the extract is estimated by Folin-Ciocalteu method. The extract exhibits significant antioxidant activity. The in vitro antioxidant activity of phenolic compounds in the methanol and acetone extract of B. lanzan root is established. Both extract shows good degree of electron donation capacity in terms of relative reductive efficiency (RRE), but methanolic extract shows more RRE (0.79) value as compared to acetone extract $(0.60)$ due to more content of phenolics. In cyclic voltammetry measurement lower oxidation potential of methanol extract shows higher antioxidant efficacy. In DPPH system, the strongest radical scavenging activity was exhibited by the methanolic extract $(\mathrm{EC} 50=$ 0.24 \pm 0.02 ) (Pareta et al., 2011).

\section{Antidiabetic and antihyperlipidemic activity}

Diabetes mellitus is a chronic metabolic disease caused by an absolute or relative lack of insulin and or reduced insulin activity. Hyperlipidemic condition is metabolic complication of both clinical and experimental diabetes (Gandhi., 2001). Low density lipoprotein in diabetic patients leads to abnormal metabolism and is associated with increase in very low density lipoprotein (VLDL) secretion and impaired VLDL catabolism. Ultimately, this leads to atherosclerotic plaque formation (Kameshra et al., 2001). Those with blood glucose levels $>190 \pm 8 \mathrm{mg} / \mathrm{dl}$ are administered the methanolic leaf extract of B. lanzan (100 or $200 \mathrm{mg} / \mathrm{kg}$, body weight) or positive control for 21 days. Blood glucose and lipid profile are evaluated.

\section{Adaptogenic activity}

Adaptogens cause an adaptive reaction to a disease and are useful in many unrelated illness and appear to produce a state of nonspecific increased resistance during stress resulting in stress protection (Alexender and Wickman 2010). The methanolic extract of $B$. lanzan leaves are evaluated for adaptogenic activity using the swim endurance model in all groups under normal and stressed conditions. Urinary vanillyl mandelic acid (VMA) and ascorbic acid are selected as noninvasive biomarkers to evaluate the antistress activity. The 24 hrs urinary excretion of VMA and ascorbic acid are determined by spectrophotometric methods. Daily administration of the extract at doses of 10 , $20,30,40$ and $50 \mathrm{mg} / \mathrm{kg}$ body weight prior to induction of stress inhibited stress-induced urinary biochemical changes in a dosedependent manner without altering the levels in normal control groups. The methanolic extract exhibited significant anti-stress activity (Mehta et al., 2011).

\section{Wound healing activity}

The ethanolic extract of $B$. lanzan fruits was used in Albino rats for wound healing activity and used to study the effect in dexamethasone suppressed wound healing. Three wound models viz., incision, excision and dead space wounds were used in this study. The 
parameters studied are breaking strength in case of incision wounds, epithelialization and wound contraction in case of excision wound and granulation tissue dry weight, breaking strength and hydroxyproline content in case of dead space wound.

The dexamethasone treated group showed a significant $(p<0.001)$ reduction in the wound breaking strength when compared to control group in incision type of wound model. Coadministration of $B$. lanzan with dexamethasone significantly $\quad(\mathrm{p}<0.001)$ increased the breaking strength of dexamethasone treated group. In-vivo wound healing supporting study mediated by carrageenan induced paw edema as antiinflammatory activity. Herbal gel was formulated incorporating one of the active ethyl acetate sub-fractions in two concentrations (1\% and 5\%). Gel was evaluated for its spreadability, $\mathrm{pH}$, color, consistency and appearance. The 5\% gel exhibited significant increase in percentage of wound contraction as well as growth in tensile strength with $177 \mathrm{~g}(\mathrm{p}<0.05)$ and $181.2 \mathrm{~g}$ ( $\mathrm{p}<0.01$ ), respectively (Mehta et al., 2014).

\section{Memory booster}

Alzheimer's disease is a progressive neurodegenerative brain disorder that occurs gradually and results in memory loss, unusual behavior, personality changes, and ultimately death (Reddy., 1997). Biochemical abnormalities such as reduction of acetyltransferase, acetylcholine biosynthases and increase in acetyl cholinesterase (AChE), and metabolism are strongly associated the degree of cognitive impairment (Ellen., 1997). Petroleum ether extract of seeds of B.lanzan (PEB) $(500 \mathrm{mg} / \mathrm{kg}$, oral) is studied for its neuro-psychopharmacological effect in experimental rats.

Activity of seeds extract on memory acquisition and retention is studied using elevated plus maze and step down apparatus models, and AChE enzyme level at discreet parts of brain is also estimated. Administration of PEB $(500 \mathrm{mg} / \mathrm{kg})$ to positive control and treated groups showed significant reduction in transfer latency in elevated plus maze, increase in step down latency in step down apparatus models and reduction of acetylcholine esterase enzyme activity in different regions of the brain as compared with the other groups (Neelkanth., 2011).

\section{Antivenom activity}

B. lanzan includes in the list of the plants which have anti-snake venom activity. Fruit and bark extract of $B$. lanzan is used for the treatment of snake bite in Chhattisgarh region (Minu et al., 2012). The ethanolic extract of $B$. lanzan bark was studied against toxicity induced by Naja kaouthia snake venom by various in vivo and in vitro studies. The extract was evaluated for neutralization of lethality, myotoxocity, phospholipase A2 activity and human red blood cell lysis produced by $N$. kaouthia snake venom. The extract at $200 \mathrm{mg} / \mathrm{kg}$ and $400 \mathrm{mg} / \mathrm{kg}$ significantly neutralized the lethality produced at different concentration of snake venom.

Myotoxicity also decreased up to a significant level characterized by decline in creatine phosphokinase level. In vitro models for assessing hemolytic activity were found to be significantly decreased in the presence of the extract. Both direct and indirect hemolytic study was performed at various concentration of extract. More than $50 \%$ of hemolysis was significantly neutralized by the extract. Results showed significant neutralization of toxicity produced by $N$. kaouthia snake venom (Hedge et al., 2014). 


\section{Value addition in chironji}

Although the kernel has more economic value, the fruits of chironji also have potential to be processed into several value added products.

\section{Fruits}

The fruit of chironji is juicy and sweet in taste. Although the juice recovery is quite less due to large seed size, the fruit can be used for preparation of various value added products like squash, ready to serve (R.T.S.) drinks and nectar after juice extraction. Fruits can also be dried locally under sun or in cabinet drier under controlled conditions and can be preserved in the form of fruit powder. Moreover, fermented beverage i.e., wine can also be prepared from the pulp of the fruits.

\section{Chironji Nuts}

Although chironji nuts and kernels have been used extensively but there is no machinery for processing of chironji nuts. The shelling of chironji nuts is usually done manually and sometimes by locally made machines. This traditional process involves soaking the seeds in water for 24 hours, skin removal by hand rubbing followed by drying. Dried nut is broken by rubbing between a pair of stone slab or hammer followed by separation of kernel from the hull (Kumar et al., 2012). The chironji nuts are then packed either in glass jars or polyethylene bags. Chironji nuts are used in preparation of many sweet preparations such as halwa, kheer, laddu, paak etc. They are also used as dry fruit in preparation of sweets.

\section{Chironji Oil}

Chironji kernel contains about 52\% oil (Kumar et al., 2012). The kernel is used for extraction of chironji oil. This extracted oil is used mostly in cosmetic manufacturing and substitute for olive and almond oils (Siddiqui et al., 2014). Sometimes this oil is also used by native people as edible oil.

Table.1 Proximate and mineral analysis of seeds of Buchanania lanzan $(\mathrm{g} / 100 \mathrm{~g})$

\begin{tabular}{|r|l|l|}
\hline S. No. & Components & Proximal value (\%) \\
\hline $\mathbf{1 .}$ & Ash & 2.20 \\
\hline $\mathbf{2 .}$ & Moisture & 3.6 \\
\hline $\mathbf{3 .}$ & Crude Fat & 38 \\
\hline $\mathbf{4 .}$ & Total Protein & 43.24 \\
\hline $\mathbf{5 .}$ & Total Carbohydrate & 12.96 \\
\hline $\mathbf{6 .}$ & Total Crude fiber & 18.50 \\
\hline $\mathbf{7 .}$ & Energy value $(\mathrm{k}$ cal) & 229.99 \\
\hline $\mathbf{8 .}$ & Phosphorus & 593 \\
\hline $\mathbf{9 .}$ & Strontium & 0.68 \\
\hline $\mathbf{1 0}$ & Zinc & 3.32 \\
\hline $\mathbf{1 1}$. & Aluminum & 0.3 \\
\hline $\mathbf{1 2}$. & Boron & 0.6 \\
\hline $\mathbf{1 3}$. & Calcium & 70 \\
\hline $\mathbf{1 4}$. & Cooper & 1.15 \\
\hline $\mathbf{1 5}$. & Iron & 4.8 \\
\hline $\mathbf{1 6}$ & Magnesium & 275 \\
\hline
\end{tabular}

Khatoon et al., 2015 
Table.2 Compound study in different solvent present in Buchanania lanzan

\begin{tabular}{|c|c|c|}
\hline S.No. & Solvent & Compound Detected \\
\hline \multirow[t]{5}{*}{1.} & \multirow[t]{5}{*}{ Petroleum ether } & Oleic Acid \\
\hline & & Tetradecanoic Acid \\
\hline & & 9-Octadecenamide \\
\hline & & $\beta$-Sitosterol \\
\hline & & 9-Octadecenoic Acid \\
\hline \multirow[t]{5}{*}{2.} & \multirow[t]{5}{*}{ Dichloromethane } & Tetradecanoic acid \\
\hline & & n-Hexadecanoic acid \\
\hline & & $\gamma$-Sitosterol \\
\hline & & Oleic Acid \\
\hline & & Octadec-9-enoic acid \\
\hline \multirow[t]{5}{*}{3.} & \multirow[t]{5}{*}{ Methanolic } & Pentadecanoic acid, 14-methyl-, methyl ester \\
\hline & & Eicosanoic acid \\
\hline & & Phenol, 2-(1-phenylethyl) \\
\hline & & Oleic acid, 3-hydroxypropyl ester \\
\hline & & n-Hexadecanoic acid \\
\hline \multirow[t]{5}{*}{4.} & \multirow[t]{5}{*}{ Ethanol-Water } & Phenol, 2, 4-bi's (1,1-dimetyletyl) \\
\hline & & Tetradecanoic Acid \\
\hline & & 2,6-Octadienal, 3,7-dimethyi \\
\hline & & Octadecanoic acid \\
\hline & & $\begin{array}{c}\text { Octadecanoic acid, 2,3-dihydroxypropyl } \\
\text { ester }\end{array}$ \\
\hline
\end{tabular}

Khatoon et al., 2015

\section{References}

Alexender P, Wickman G. Effects of adaptogens on the central nervous system and the molecular mechanisms associated with their stress: Protective activity.

Pharmaceuticals 2010;3(1):188-224.

Choubey A, Prasad R, Choubey OP, Pant NC et al., Some aspects of germination studies in Buchanania lanzan Spreng. seeds. J Tropical Forestry. 1997; 13(11):65-73.

Ellen YS, Kathryn MU. Donepezil: Anti cholinesterase inhibitor for Alzheimer's disease. Am J Health Syst Pharm 1997;54:2805-10.

Gandhi HR. Diabetes and coronary artery disease Importance of risk factors.
Cardiol Today 2001;1:31-4.

Hegde K, Naseeb KM, Syed A, Deepak TK. Kalangottil A. Evaluation of antivenom activity of ethanolic extract of Buchanania lanzan bark against Naja kaouthia snake venom. Unique J Pharm Biol Sci 2014;2(2):39-45.

Kamesara, B.R, R, Kesavulu MM, Apparao $\mathrm{CH}$. Effect of oral administration of bark extracts of Pterocarpus santalinus L. on blood glucose level in experimental animals. Ethnopharmacol 2001;74(1):69-74.

Khare CP. Indian Medicinal Plants: An Illustrated Dictionary. Berlin Heidelberg New York: Springer; 2007. p. 104.

Khatoon, N., Rajinder K. Gupta, Yogesh K. Tyagi. Nutraceutical potential and phytochemical screening of Buchanania 
lanzan, an underutilized exotic Indian nut and its use as a source of functional food Journal of Pharmacognosy and Phytochemistry 2015; 4(1): 87-94

Kirtikar KR, Basu BD. Indian Medicinal Plants: Lalit Mohan Basu, 2nd ed., Allahabad, 1935, III.

Kumar, J.; Vengaiah, P. C.; Srivastava, P. P. and Bhowmik, P. K. (2012). Chironji nut (Buchanania lanzan) processing, present practices and scope. Indian J. Traditional Knowledge, 11(1): 202-204.

Mehta BK, Pattnaik A, Kumar A. Enhancement and validation of wound healing activity with herbal gel formulated from sub-fraction of Buchnania lanzan Spreng. bark extract. Int J Pharm PharmSci 2014;6(7):281-6.

Mehta KS, Mukherjee S, Jaiprakash B. Antiinflammatory activity of the methanolic extract of Buchanania lanzan leaves by Carrageenan-induced rat paw oedema method. Int J Pharm Sci Rev Res 2011;6(2):144- 6.

Mehta KS, Nayeem N, Bains N. Adaptogenic activity of methanolic extract of Buchanania lanzan leaves an experimental study in rat model. Pharm Sinica 2011;2(3):107-12.

Mehta SK, Jaiprakash B, Nayeem N. Isolation and phytochemical investigation on leaves of Buchanania lanzan (Chironji). Ann Biol Res 2011;2(3):469-73.

Mehta SK, Mukherjee S, Jaiprakash B. Preliminary phytochemical investigation on leaves of Buchanania lanzan (Chironji). Int J Pharm Sci Rev Res 2010;3(2):55-9.
MH, Duragkar NJ, Bhusari KP. Antiinflammatory and antioxidant activities of methanolic extract of Buchanania lanzan Kernel. Indian J Pharm Educ Res 2010;44(4):363-8.

Minu V, Harsh V, Ravikant T, Paridhi J, Noopur S. Medicinal plants of chhattisgarh with anti-snake venom property. Int $\mathrm{J}$ Curr Pharm Rev Res 2012;3(2):1-10.

Nasim KT, Arya R, Babu V, Ilyas M. Myricetin 3'-rhamnoside-3-galactoside from Buchanania lanzan (anacardiaceae). Phytochemistry 1992;31(7):2569-70.

Neelakanth MJ, Bhat MR, Taranalli AD, Veeresh B. Effect of Buchanania lanzan seeds on learning and memory in normal and memory deficit rats. J Res Pharm Biomed 2012;22(1):33-8.

Pareta SK, Harwansh RK, Kumar KJ. Antioxidant activity of Buchanania lanzan Spreg. F: Anacardiaceae. Pharmacol Online 2011;1:733-9.

Reddy DS. Assessment of nootropic and amnestic activity of centrally acting agents. Indian J Pharmacol 1997;29:208-21.

Siddiqui, M. Z.; Chowdhury, A. R.; Prasad, N. and Thomas, M. (2014). Buchanania lanzan: a species of enormous potentials. World J. Pharm. Sci., 2(4): 374-379.

Singh J, Patra AK, Nandeshwar DL, Meshram PB, Negi KS. Effect of growth regulators on the rooting of root cuttings of Chironji (Buchanania lanzan Spreng). Proceedings of National Workshop on Conservation of Medicinal Plants; 2002. p. 128.

\section{How to cite this article:}

Neeraj, Vinita Bisht, Shalini Purwar. 2020. Chironji (Buchanania lanzan) Wonder Tree: Nutritional and Therapeutic Values. Int.J.Curr.Microbiol.App.Sci. 9(02): 3033-3042. doi: https://doi.org/10.20546/ijcmas.2020.902.349 